\title{
The CMA's assessment of customer detriment in the UK retail energy market
}

\section{Stephen Littlechild ${ }^{1,2}$ (C)}

Published online: 19 June 2020

(c) The Author(s) 2020

\begin{abstract}
In 2016, the UK Competition and Markets Authority (CMA) found that "weak customer response" enabled incumbent UK energy retailers to set higher and discriminatory prices to residential customers. The CMA estimated the associated higher prices constituted a customer detriment in the range $£ 1.4$ bn to $£ 2$ bn per year. Although the CMA recommended against a price cap on most domestic energy tariffs, the size of the detriment and public concern about "rip-off energy tariffs" nonetheless led the Government to impose a price cap as from January 2019. This paper examines the CMA's calculation of customer detriment and suggests that it is inconsistent with CMA Guidelines and unprecedented with respect to its nature, magnitude and policy impact. Alternative more realistic calculations suggest that any detriment would have been nearly an order of magnitude lower, so that a price cap was inappropriate. This raises a number of questions about the CMA's approach.
\end{abstract}

Keywords Retail energy market · Weak customer response · Customer detriment

JEL Classification L94 · L970 · L51

This is a further revision and reorientation of an earlier paper (Littlechild 2017a, 2018a). I am grateful to Monica Giulietti, Eileen Marshall, Bruce Mountain, Robert Ritz, Tim Tutton, Catherine Waddams and several industry colleagues for helpful comments, and especially to two patient referees for pointing out an earlier error, challenging the argument, suggesting improvements, and demanding more clarity.

Stephen Littlechild

sclittlechild@tanworth.mercianet.co.uk

1 Emeritus Professor, University of Birmingham, Birmingham, UK

2 Cambridge Judge Business School, Cambridge, UK 


\section{Introduction}

Following concerns about rising energy prices and about its own regulatory policy, the Office of Gas and Electricity Markets (Ofgem) in 2014 asked the Competition and Markets Authority (CMA) to review the UK energy market. ${ }^{1}$ It specified five issues for particular examination, including "weak customer response". In its Final Report, the CMA (2016) found "an overarching feature of weak customer response" in the domestic (i.e. residential) retail market which had an "adverse effect on competition". This gave market power to the six large former-incumbent suppliers, enabling them to engage in price discrimination against less engaged customers (elsewhere called a "two-tier market" or a "loyalty penalty") and to make excess profits and/or to operate inefficiently.

The CMA's "preferred estimate" of customer detriment in the form of higher prices was an average of $£ 1.4$ bn per year over 2012-2015, rising to almost $£ 2$ bn in 2015 (where $£ 1=\mathrm{US} \$ 1.33$ in June 2016). On average, $£ 1.4$ bn represented 9\% of the bill of a dual fuel customer. The CMA considered but rejected the remedy of a widespread price cap, and recommended instead that Ofgem should experiment with different ways of promoting greater customer engagement and switching. However, in a note of dissent, one member of the CMA panel recommended in addition a temporary widespread price cap because of the size of the customer detriment and the limited effectiveness to date of measures to promote customer engagement.

After considerable political debate, often citing the magnitude of this detriment, in July 2018 the Tariff Cap Act required Ofgem to impose a cap on most domestic energy tariffs. Meanwhile, the CMA has since found "loyalty penalties" of $£ 4$ bn in other consumer markets and proposed various interventions there including the possibility of price controls.

Several aspects of the CMA report and methodology have been critically appraised by the present author and others. ${ }^{2}$ Given the impact that the CMA's calculation of customer detriment has had on policy, the present paper seeks to better understand and appraise that calculation, in the context of previous investigations by UK competition authorities.

Section 2 looks at how previous UK competition authority investigations of other markets, particularly the cement market, have used two different approaches (which the CMA called 'direct' and 'indirect') to estimate customer detriment. Section 3 examines the CMA's preferred so-called 'direct approach', involving the characterisation of a 'well-functioning retail energy market' that it used as a benchmark against which it calculated customer detriment. The paper argues that the CMA's benchmark was a long-run equilibrium concept inconsistent with the CMA's own Guidelines, quite different from the method used earlier to calculate detriment in the cement market; it was also based on unrealistic assumptions. Section 4 explores some arguably more realistic assumptions about customer response and the costs and capacities of different suppliers, which suggest a much smaller detriment. Section 5 briefly

\footnotetext{
${ }^{1}$ Strictly speaking, the policy and the present paper refer to Great Britain (that is, the UK excluding Northern Ireland) but the term UK is more familiar internationally.

${ }^{2}$ E.g. Littlechild (2014, 2016a, 2016b, 2017b, 2018b, 2019, 2020a); joint submissions with other former GB energy regulators to the CMA and Parliament e.g. Littlechild et al. (2016a, b, 2017); and views of other UK regulatory economists at a late stage of the CMA process (e.g. Yarrow 2015; Deller et al. 2016).
} 
examines the CMA's 'indirect approach', showing that adding inefficient cost to excess profit, which previous investigations have not done, greatly increases the size of the detriment. Section 6 summarises the findings and raises some questions about the future conduct of CMA investigations. Further background on the UK energy sector, and discussion of the CMA's 'indirect approach', are available elsewhere. ${ }^{3}$

\section{Competition authority calculations of customer detriment}

\subsection{Previous investigations that quantified customer detriment}

When a market is referred to it for investigation, the CMA is required to decide whether 'any feature, or combination of features, of each relevant market prevents, restricts or distorts competition'. If so, this constitutes an Adverse Effect on Competition (AEC), and the CMA is required to decide whether to take or recommend action to remedy, mitigate or prevent any detrimental effects on customers. Detrimental effects could be higher prices, lower quality, or less choice or innovation.

The 2003 Guidelines developed by the CMA's predecessor body the Competition Commission (CC) suggested that the $\mathrm{CC}$ would normally consider the effectiveness of competition by looking at five different types of indicators. ${ }^{4}$ The CC/CMA revised 2013 Guidelines discussed prices and profitability as well as some non-price indicators. These Guidelines noted that, as a benchmark against which to measure an AEC, 'the CC uses the term 'a well-functioning market' in the sense, generally, of a market without the features causing the AEC, rather than to denote an idealized, perfectly competitive market". (para 30) A "well-functioning market" is "one that displays the beneficial aspects of competition as set out in paragraphs 10 to 12 " where paragraph 10 summarised the concept of competition as a process of rivalry. ${ }^{5}$ Neither of the Guidelines suggested that an investigation was required to quantify any customer detriment, or had much more to say about how it might do this.

There have now been 21 completed market investigations since the Enterprise Act 2002 made provision for them. In 10 cases the detriment was not explicitly quantified (though there were sometimes some hypothetical and partial calculations). In the other 11 cases, two types of method were used to quantify detriment: a comparison of observed prices against a conjectured and generally cost-based competitive

\footnotetext{
3 In an online version of this paper (Littlechild 2020b), Appendix 1 provides further background on the UK retail energy market, Ofgem's regulatory policy, the CMA investigation and report, implementation of its remedies, and the Government tariff cap. Appendix 2 examines the CMA's 'indirect approach', and also suggests that excess profit in the domestic sector was significantly lower than the CMA's estimate.

4 These were (a) Prices and their adjustment over time, (b) Profitability in relation to the cost of capital but perhaps looking also at the efficiency of costs, (c) International price comparisons, and (d) Other indicators such as innovation and efficiency. (paras 3.78-3.90).

5 " 10 . Competition is a process of rivalry as firms seek to win customers' business. It creates incentives for firms to meet the existing and future needs of customers as effectively and efficiently as possible-by cutting prices, increasing output, improving quality or variety, or introducing new and better products, often through innovation; supplying the products customers want rewards firms with a greater share of sales. Beneficial effects may also come from expansion by efficient firms and the entry into the market of new firms with innovative products, processes and business models, and the exit of less successful ones."
} 
benchmark price (what the CMA Energy investigation called the 'direct' approach) and a more conventional accounting-based calculation of excess profit (what the same investigation called the 'indirect approach'). In six of these latter 11 cases, both methods were used, in the other five just one or other method. ${ }^{6}$

Table 1 shows the estimated annual detriments in the 11 cases where they were quantified. The competitive benchmark estimates are generally larger and less precise than the excess profit estimates. Excluding Energy, and the exceptional PPI investigation where it was said that PPI profits were used to cross-subsidise the provision of credit, all the detriments are in the tens or low hundreds of $£$ m: the median detriment is $£ 64 \mathrm{~m}$ via excess profit and $£ 92 \mathrm{~m}$ via a competitive benchmark. In contrast, Energy found average annual detriments of $£ 720 \mathrm{~m}$ and $£ 1400 \mathrm{~m}$ via the two methods, and $£ 2$ bn in 2015 , more than an order of magnitude greater than found in any other report. The Energy detriment is between 20 and 67 times higher than in Groceries (joint second-largest detriment in Table 1 excluding PPI).

Of course, the markets investigated were of different sizes, but the Energy detriment was large despite that. For example, the detriment estimates ranged from under $1 / 2 \%$ to about $13 \%$ of the value of the market. The preferred estimate of $£ 1.4$ bn detriment in Energy represented $9 \%$ of the average residential bill (Final Report Table 2 para 195), which is a higher proportion of market value than other preferred estimates except for Private Healthcare at $10 \% .^{7}$ The Energy estimates were also high in relation to company profits. ${ }^{8}$

\subsection{Quantification using a competitive (cost-based) benchmark}

Of the eight previous investigations in Table 1 that attempted to calculate the customer detriment of an identified AEC by comparing actual prices with those that were estimated would obtain in a competitive market, four of them used rather detailed and situation-specific calculations that do not seem particularly relevant to Energy. ${ }^{9}$ Another investigation was overtaken by a Government decision to impose a

\footnotetext{
6 Sometimes a range of values was given. The estimates were often accompanied by comments about the difficulty of making such calculations, about the existence of other unquantifiable factors, and to the effect that detriments were 'at least' of the cited amounts. In some reports, notably on Energy, large amounts of data were redacted $[\&]$ so the calculations are often unclear.

7 Thus, in Store cards, LPG and Cement the CC preferred detriment estimates of $8 \%, 3 \%$ and $4 \%$, respectively, to those of $13 \%, 11 \%$ and $13 \%$ respectively. In Energy, if the $£ 1.4$ bn average detriment corresponded to $9 \%$, the $£ 2$ bn detriment in 2015 might be of the order of $13 \%$, which exceeds that of Private Healthcare.

8 The Groceries detriment at "approximately $£ 105-£ 125 \mathrm{~m}$ a year ... represents around 3 per cent of the combined annual profits of $£ 3.6$ bn that the four largest grocery retailers earned in 2007". (Groceries para 6.54) In contrast, in Energy, the average profit-based detriment of $£ 720 \mathrm{~m}$ was two thirds of the annual profits of the six largest energy suppliers (which averaged $£ 1.1$ bn over 2012-2015 per Ofgem’s segregated accounts); the average cost-based detriment of $£ 1.4$ bn was one and a quarter times that same average annual profit; and the detriment of $£ 2$ bn in 2015 was almost precisely double the profit that year.

9 Thus, Groceries drew on an econometric analysis finding that an additional store in the neighbourhood reduced average profit margins by $3.8 \%$ on average. This gave an average reduction in profits per store which, multiplied by the number of existing stores, gave an estimate of the detriment caused. PPI estimated the annual net deadweight welfare losses from people not buying PPI at (too) high prices and from buying credit at (too) low prices. Local Bus Services estimated the consumer surplus associated with an increased frequency of service. Private motor insurance estimated how much costs could be reduced if parties had more aligned incentives to minimise costs.
} 


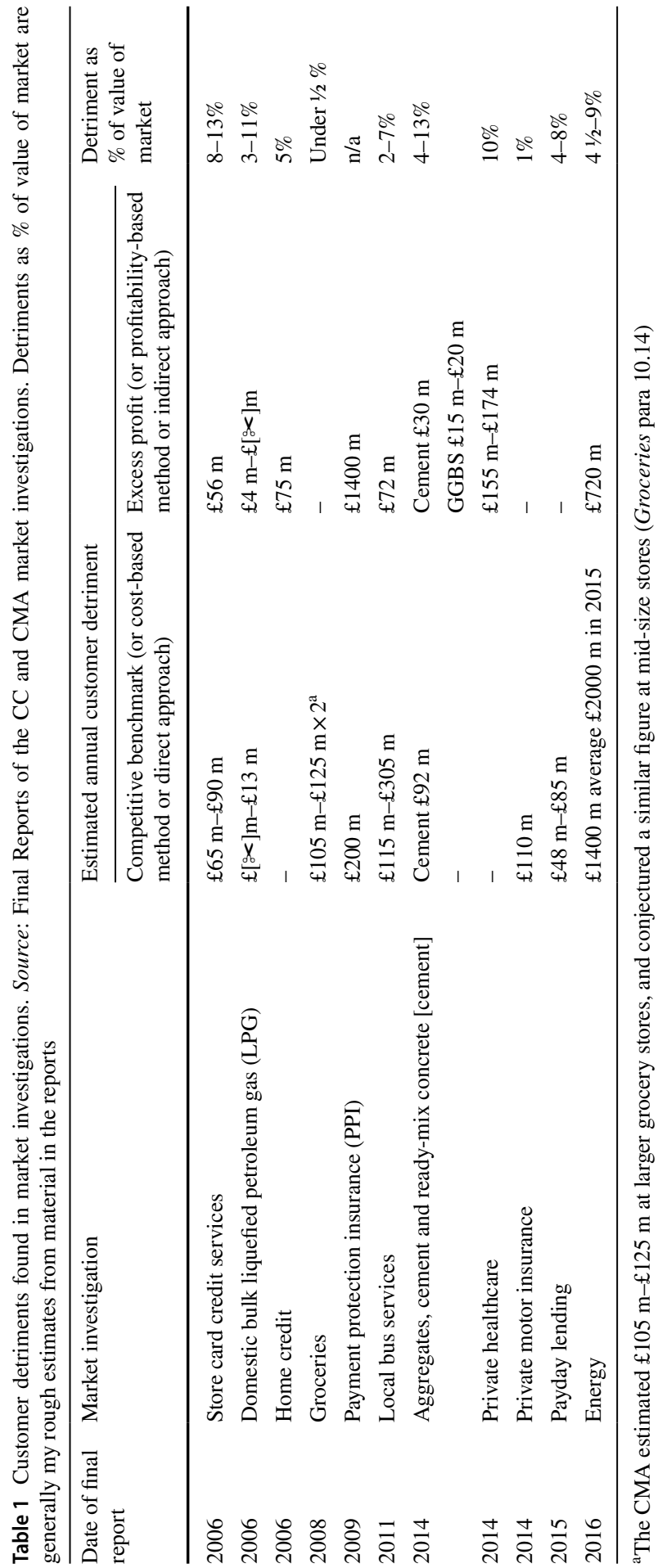


price control, and a particular price reduction was assumed without much attempt to calculate what price would obtain in a well-functioning market. ${ }^{10}$ This leaves three market investigations as closer comparators to Energy.

The Store Card Credit Services investigation found that there was insufficient competitive pressure on Annual Percentage Rates (APRs) charged by these stores. It estimated the customer detriment by comparing "the prices actually paid by cardholders with what prices would have been if they had reflected costs, including the cost of capital". ${ }^{11}$

The competition issue in Domestic Bulk LPG was limited customer switching between the four major suppliers, thus not dissimilar to that in Energy, albeit the market was much smaller. ${ }^{12}$ To estimate the customer detriment in terms of higher prices, the CC compared the prices actually charged by each supplier against the lowest non-introductory price that it charged. ${ }^{13}$

In Cement, the CC found that coordination between the five major cement producers limited the extent of price competition. To estimate a competitive benchmark price of cement, it constructed a competitive industry supply curve based on the unit cost for each plant, assumed constant up to its level of present capacity. Then the intersection of this supply curve with the present level of demand yielded an estimated competitive market-clearing price (see next subsection).

\footnotetext{
${ }^{10}$ The investigation of PayDay Lending had only just started when media criticism of the practice became so vocal that the Government announced that it was going to require the Financial Conduct Authority (FCA) to impose a price control. The CMA and FCA liaised closely. The CMA's calculation of detriment was based on a seemingly arbitrary reduction in the average monthly interest rate from 30 to $25 \%$, and a month later the FCA announced its intention to impose a price control at essentially that level. The CMA accepted that about 160,000 customers would no longer be able to get payday loans, because they would no longer be profitable to serve, but considered that these customers would be prompted to seek debt advice, and "Apart from a short initial period we believe these customers will be better off not having taken out a loan". (FCA para 1.27).

${ }^{11}$ It estimated that "in broad terms actual store card APRs were on average some 10 to 20 per cent above what they would have been had they reflected providers' costs across the sector as a whole, including the cost of capital; thus average sector APRs have averaged some 26.5 per cent compared with our calculation for cost reflective APRs of some 22 to 24 per cent" (Store Card Credit Services, paras 9.10, 9.11).

${ }^{12} L P G$ seems to have been the smallest market investigated - certainly it had the smallest estimated customer detriment—by an order of magnitude—in Table 1. LPG was used by fewer than 150,000 UK households in rural areas who did not have access to the mains gas grid. The rate of customer switching between LPG suppliers was low, even among customers who could obtain significant net savings by switching. Partly there was cost and inconvenience because changing supplier meant changing the fuel tank. But customers had little awareness of alternative suppliers. "Individual suppliers also charge different prices to different customers, largely unrelated to differences in cost. Low switching rates exist, despite the availability of lower prices from other suppliers and despite little evidence that customers have any loyalty towards, or preference for, the service of, their existing supplier" ( $L P G$ para 7 ). "... the major suppliers have made efforts to compete on non-price factors, but [we] found little evidence that customers perceive differences in quality of service between suppliers" ( $L P G$ para 9).

13 "We began by identifying the lowest non-introductory price charged in Great Britain by each major supplier to a substantial number ([\&<] per cent) of its customers in 2003. For each customer of the major suppliers, we calculated the premium (if any) paid above this price and multiplied this by the customer's annual consumption in 2003." ( $L P G$ para 4.80) The CMA main report did not give figures, instead commenting that "the cost to customers cannot be measured accurately", and "alternative approaches lead to a range of figures", although an Appendix mentions an upper figure of $£ 13 \mathrm{~m}$.
} 
Three points might be made about these three studies. First, these three investigations generally express some reservations about the accuracy of their cost-based estimates of the price that would obtain in a well-functioning competitive market, and hence about the associated estimates of customer detriment. All of them seem to give greater weight to their alternative and lower profit-based calculations of detriment. $^{14}$

Second, none of these three investigations challenged the efficiency and costs of the market participants. Those parameters were taken as given, and the question was whether a competitive market price would be lower as a result of a lower markup on cost, or a more efficient allocation of output between the parties. Similarly, none of them sought to augment the calculation of excess profit by adding in an estimate of inefficient cost.

Third, none of these three markets was politically sensitive, and no remedial action was considered that was as invasive or as politically sensitive as a price cap. Nor was the presentation of the estimates of customer detriment such as to call into question the recommended remedies.

\subsection{The CC's cement market investigation}

The CC's investigation in Cement shows how a different competition panel approached similar issues to those in Energy and in important respects took a significantly different approach. ${ }^{15}$ It also provides a simple graphical model for illustrating the two different calculations of customer detriment.

The investigation covered the market for cement and related products. There were four main cement companies, plus some imports. The $\mathrm{CC}$ expected vigorous price competition. ${ }^{16}$ But it did not observe this: rather, it found "a combination of structural and conduct features in the GB cement markets that gave rise to an AEC in those markets through coordination ... The likely effect of these features is higher prices of cement in GB than would otherwise be the case". (Cement paras 4, 6, p 1) The CC used two approaches to estimate the extent of this.

"Using the profitability-based approach, we estimate the annual customer detriment from high cement prices to be of the order of $£ 30 \mathrm{~m}$ per year on average for the period 2007 to 2012 ." The average excess profit was $£ 3.20$ per ton. There

\footnotetext{
14 Thus, Store Card Credit Services estimates that customer detriment is "possibly significantly more" than the profit-based estimate but generally cites the latter. $L P G$ notes its cost-based estimate then says "but alternative approaches lead to a range of figures". (para 4.80) Cement notes its cost-based calculation then qualifies with "However, we think that this estimate is likely to represent an overestimate of the customer detriment,..." (para 96) and referred to it as "a useful secondary point of reference".

15 The CC and CMA appoint a panel of about six members to conduct each case. The chairman of the CC Cement panel was Professor Martin Cave, who was later the dissenting member of the CMA Energy panel. One other member was on both panels.

16 "In a well-functioning market, faced with a demand slump, significant excess capacity and high fixed costs, we would expect that market participants would compete vigorously on price to maintain volumes, resulting in greater volatility in shares and significant erosion of margins with returns at or below the cost of capital". (Cement para 34).
} 
was, however, great variation over time, ${ }^{17}$ and this approach likely yielded an underestimate. $^{18}$

Such accounting approaches have been subject to criticism by economists (e.g. Fisher and McGowan 1983), although defended by others (e.g. Long and Ravenscraft 1984), and the debate does not seem to have discouraged their use. In fact, Fisher (2002) made similar points in a short submission to the CC (2002) investigation into SME Banking, on behalf of one of the banks, explaining why high accounting rates of return did not necessarily imply monopoly profits, why real markets were not always in long-run equilibrium, and why profits had an important role in the process of competition over time. ${ }^{19}$ At the time, the CC seemed favourably disposed to this argument-provided it could still use a return equal to the cost of capital as its benchmark. ${ }^{20}$

The second, cost-based, approach involved comparing average cement prices against a benchmark price that would prevail in a well-functioning market. This yielded "a total customer detriment of $£ 92 \mathrm{~m}$ in 2011 . This is comparable with an estimated detriment of $£ 78 \mathrm{~m}$ in 2011 using the profitability-based approach." There were of course qualifications here too, ${ }^{21}$ and the profitability-based estimate was used as the baseline, albeit likely to be an underestimate over a full business cycle.

\footnotetext{
${ }^{17}$ The CC calculated excess industry profit as the industry return (after impairment losses due to lower asset values as a result of the unexpected slump in demand in 2007) less a cost of capital of $10 \%$, multiplied by capital employed. Over the period 2007-2012 the excess profit ranged from minus $£ 41.5 \mathrm{~m}$ to $£ 78.6 \mathrm{~m}$ with an average of $£ 29.4 \mathrm{~m}$ per year. Average excess profit per tonne varied from minus $£ 4.00$ to $£ 9.00$, with an average of $£ 3.20$.

18 "We think that this [profitability-based] estimate underestimates the scale and significance of customer detriment in the future because the period that we have investigated includes a very severe and prolonged economic downturn and because our analysis did not cover a complete business cycle." (Cement App 8.6 para 2).

19 " 6 . ... While it is true that in long-run competitive equilibrium, economic profits are zero and the economic rate of return (adjusted for risk) is equal to the risk-free interest rate, it is very much not the case that economic profits are generally zero in competitive industries. The pursuit and attainment of profits is the engine that drives the competitive economy. To use another metaphor, the "Invisible Hand" works through profits and losses. Only when (if ever) the "Invisible Hand" is finished working will economic profits be zero. Too often, economists are so fascinated by the beautiful properties of equilibrium, especially long-run competitive equilibrium, that they forget that real markets are not always in such a state. Profits play a major and useful role in competition." (CC SME Banking 2002, p 109).

20 "2.415. We also considered whether we should allow a margin above the cost of capital to reflect more general considerations of competition. It could, for example, be argued that competition not only is a force driving down costs to their most efficient level and prices to the minimum consistent with companies being able to finance themselves, but also has a more dynamic role through time. Thus, competition drives resources to their most efficient use, creating both pressure and incentives for companies to expand or contract production as determined by consumer preferences, and to innovate by investment in new products or processes. Profits play a role in this process by signalling where demand is rising or falling, where resources are most efficiently deployed etc; and by creating the incentives necessary to bring about appropriate resources. In essence, we accept this argument. We nonetheless regard returns equal to the cost of capital as an appropriate long-term benchmark for most or all of the suppliers in a market, and towards which fully effective competition would normally drive the market...." (CC SME Banking 2002, p 109).

21 “.... we noted that our cost-based estimate is based on a single year's data (2011) and that it is based on a model where, necessarily, we have had to make significant simplifying assumptions. On the other hand, we considered that the cost-based approach to estimating the detriment is less likely than the profitability-based approach to be affected by the point in the business cycle at which the analysis is carried out." (CC Cement 2014, Appendix 8.6 p 1).
} 
Under the cost-based approach, the CC estimated a competitive benchmark price of cement by calculating a competitive industry supply curve based on an assumed unit cost for each plant. The $\mathrm{CC}$ argued that the price thus calculated, given the quantity demanded, would be the competitive market price in that particular year. It did not argue that such a price would be sustainable over time, or represented a long run equilibrium.

Figure 1 reproduces (with some added numbers and labelling) a Figure from the CC Cement report to illustrate its cost-based approach. ${ }^{22}$ The CC constructed a short-run competitive supply curve by ranking the existing cement plants in order of increasing operating cost per tonne, assumed constant up to each plant's level of capacity. ${ }^{23}$ Operating cost included the plant's site fixed cost plus its variable cost and distribution cost. It excluded divisional and central fixed costs, depreciation and cost of capital, which were all considered sunk and irrelevant to the determination of competitive output and market price. Demand for cement was taken as given and equal to realised demand in 2011. The CC then defined the competitive market price as the operating cost of the highest cost plant $\mathrm{C}$ required to meet demand (viz $£ 69.50$ per tonne). It measured the customer detriment in 2011 as the difference between actual market price then ( $£ 80$ per tonne) and the calculated competitive market price ( $£ 69.50$ per tonne), that is, around $£ 10.50$ per tonne, multiplied by the annual demand $(8.78 \mathrm{~m}$ tonnes), to give a total detriment of $£ 92 \mathrm{~m}$. This area is labelled Overcharge in the thin rectangle at the top of Fig. 1.

Cement companies argued against this benchmark. ${ }^{24}$ The CC conceded that it was a short-term concept and likely to be an overestimate of detriment. ${ }^{25}$ And the CC referred to this calculation as "a useful secondary point of reference", relative to its preferred "baseline estimate" based on its profit calculation.

One might wish to check a few details of the cost calculations to make sure they properly recover ongoing fixed costs. ${ }^{26}$ Subject to that, this seems a reasonable approach in principle, at least for the cement sector. And note that the CC makes

\footnotetext{
${ }^{22}$ Cement Appendix 8(6)-8, Fig. 1. The CC's Fig. 1 shows only four representative plants labelled A, B, $\mathrm{C}, \mathrm{D}$, whereas in fact the four major producers had 14 plants in the UK.

${ }^{23}$ The CMA found some barriers to building new plant, but not to increased output of each existing plant within its existing capacity. There was some scope for imports but they had higher costs and presented limited competitive challenge.

${ }^{24}$ For example, Lafarge said that price should reflect a Cournot equilibrium, with competitive price above cost rather than equal to it. Hanson said that the price did not allow some firms to recover total economic costs, including depreciation and a return on capital. Contrary to the CC's Guidelines, the model was "highly theoretical and stylized, near to a world of perfect competition" (Cement para 71).

${ }^{25}$ The CC agreed that its model was not the only possible benchmark, and could be interpreted as a lower bound for the competitive price. It acknowledged that, "because the benchmark we use is based on a relatively short-term model of competition, some of the less efficient plants may not be able to recover costs of capital in equilibrium". (Cement para 73) The CC admitted that "this estimate is likely to represent an overestimate of the customer detriment, because the model we use to derive this estimate is a relatively short-term model of competition which considers costs of capital as sunk, and because the model we use does not take into account the possibility of oligopoly competition." (Cement Appendix A8.6 para 96).

${ }^{26}$ For example, by excluding depreciation did the operating cost nonetheless include the cost of bringing forward any future investment as a result of operating the plant in this period, and was the operating cost in the chosen year representative of a run of years? And if it was assumed that divisional and central
} 


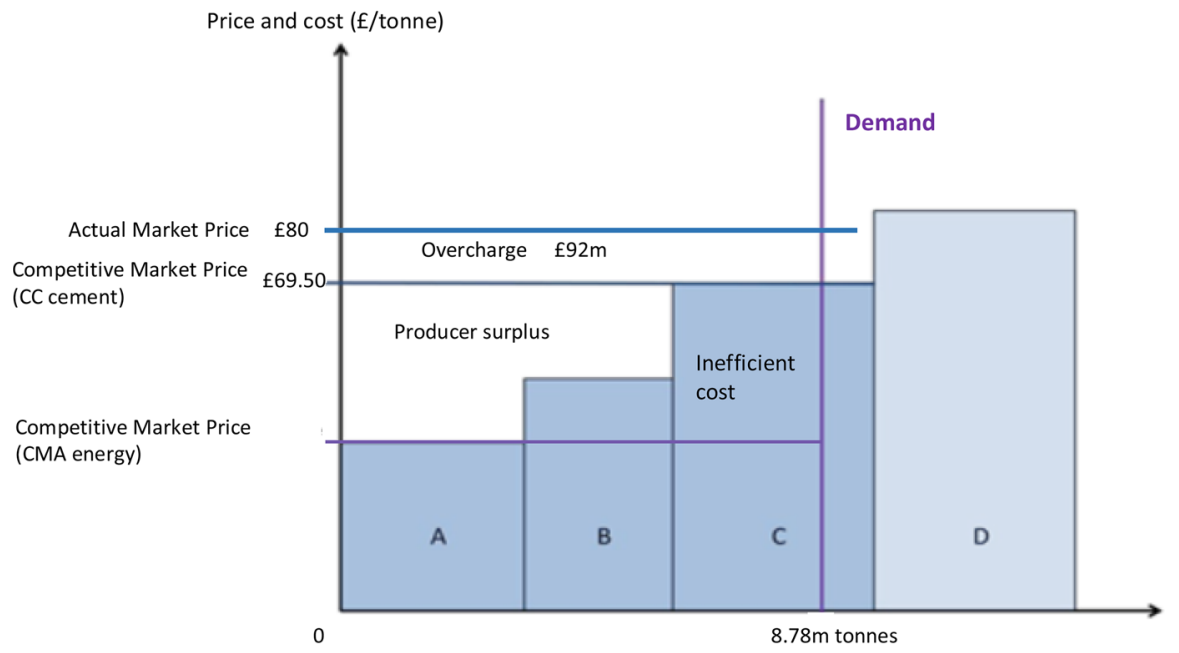

Fig. 1 Comparison of CC and CMA calculations of customer detriment: cement market

no suggestion that it is surprising or unreasonable to find plants of different operating efficiencies coexisting at a point in time, or that the higher cost ones should be excluded in an estimation of the competitive price level.

Looking ahead, the diagram may be used to contrast the CC's calculation with that of the CMA in Energy. As explained in the next section, the CMA defined the competitive retail energy market price as (approximately) the operating cost of the lowest cost, most efficient supplier A, rather than that of the highest cost, least efficient supplier $\mathrm{C}$. Thus, in terms of the labels on this diagram (inserted by the present author), the $\mathrm{CC}$ in Cement defined customer detriment as Overcharge, but the CMA in Energy defined it as Overcharge plus Producer surplus plus Inefficient cost. Not surprising, then, that there was a significant difference in the level of customer detriment.

\section{The CMA energy market investigation: direct approach}

\subsection{Constructing the benchmark}

The CMA found that weak customer response gave the six large suppliers market power which they used to engage in price discrimination and make excess profits.

Footnote 26 (continued)

fixed costs, depreciation and cost of capital would be recovered at other points of the business cycle, was there a danger that the competition authority would regard these subsequent prices and profit levels as too high? See Harris $(2015,2019)$. 
However, the CMA's stance on price discrimination was ambiguous, arguably evasive and inconsistent (Littlechild 2020b, Appendix 1.2). The CMA did not acknowledge that price discrimination could be an efficient means of sharing costs rather than of securing excess profit: that is, a 'two-tier market' with active customers paying marginal cost and less active customers sharing overhead costs could be the outcome of a competitive market. Nor did the CMA note that an extensive economic literature showed that price discrimination could be beneficial and a means of competing, or indeed that competition could force firms to discriminate. Yet while criticising the suppliers for price discrimination, the CMA found that Ofgem's attempt to prevent discrimination had reduced competition and the CMA explained why it would not attempt that either.

The focus of the CMA's criticism is actually on excess prices and profits. The CMA explained how it estimated the detriment associated with weak customer response in the retail energy market.

10.5 We have adopted two approaches to assessing the extent to which prices are excessive (i.e. have exceeded those we would expect in a well-functioning market): (a) A 'direct' approach, which involves comparing the average prices charged by the Six Large Energy Firms with a competitive benchmark price which is based on the prices charged by the most competitive suppliers, adjusted to allow for a normal return on capital and where appropriate for differences in suppliers' size, rate of growth and the cost elements that are outside of their control.

(b) An indirect approach, which involves assessing both: (i) the Six Large Energy Firms' levels of profitability (and in particular whether the return on capital employed by such suppliers exceeds their cost of capital); and (ii) the extent to which the Six Large Energy Firms have incurred overhead costs inefficiently (i.e. whether costs are higher than we estimate an efficient supplier would incur). (Final Report p 599. ${ }^{27}$ )

The present Sections 3 and 4 consider the 'direct' approach, which corresponds to the CC's cost-based approach. Section 5 briefly considers the 'indirect' approach, summarising calculations that are set out in greater detail elsewhere (Littlechild 2020b, Appendix 2).

The direct approach did not involve comparing prices actually charged by the large suppliers versus those of other suppliers on a like for like basis (i.e. variable tariff $\mathrm{v}$ variable tariff and fixed tariff $\mathrm{v}$ fixed tariff). Rather, it involved comparing the average price charged by the large suppliers against the price assumed to be charged by 'a hypothetical construct, a 'supplier' that is a combination of the suppliers that we have identified as being the most competitive in the markets". (para 10.18) The CMA summarised its methodology in a number of steps. ${ }^{28}$ The benchmark was

\footnotetext{
27 Unless otherwise obvious from the context, subsequent paragraph and page references are to the CMA Final Report.

28 "10.19 ... (a) First, we choose the suppliers that will provide the basis for our assessment of competitive benchmark prices. (b) We then consider whether an uplift is needed to their prices in order to generate revenue that would allow an energy supplier which has reached an efficient scale and is in steady state to earn a normal rate of return. (c) After that we adjust our data to account for exogenous cost dif-
} 
based on Ovo and First Utility, two of the four mid-tier suppliers, who in aggregate supplied around $4-5 \%$ of the domestic energy market. The CMA excluded two other mid-tier suppliers that it considered were atypical. ${ }^{29}$ The calculations covered the period Q1 2012 to Q2 2015.

The CMA then made various adjustments along the lines indicated. These were necessary because "the most competitive suppliers" were generally not earning a normal or even positive return on capital, were sometimes an order of magnitude smaller than the large suppliers, were often growing fast, and to differing extents were exempt from social and environmental charges that applied only to larger suppliers. The CMA calculated that, on average, the tariffs of the large suppliers were about $9 \%$ above the benchmark level. It concluded

10.50 Average detriment is assessed at $£ 1.4$ bn a year over the period as a whole, with an upward trend, reaching almost $£ 2$ bn in 2015 . Our view is that this may represent not simply a deterioration in competitive conditions over time but also an emerging revelation of the scale of detriment, as the larger Mid-tier Suppliers have begun to operate at scale and reposition their tariffs to be more competitive through the process of price discovery. Therefore we attach somewhat greater significance to the more recent results.

The CMA acknowledged that its calculated customer detriment was similar to the annual profits of the six large suppliers, and explained that this reflected their inefficiency. This meant that, at the calculated competitive price, these suppliers would not merely lose their excess profits, they would actually make losses unless they could increase their efficiency. ${ }^{30}$

Footnote 28 (continued)

ferences between the suppliers arising from differences in their customer mix. (d) We then compute the average bill for each supplier by payment type and the benchmark average bill, and use those to calculate the extent to which suppliers' bills are priced above the competitive level, as implied by the benchmark bills. (e) After that, we calculate the overall detriment to domestic customers from the prices being set by the Six Large Energy Firms above the competitive level. (f) Finally, we consider the robustness of our findings by performing the analysis of bills at different consumption levels and by comparing detriment estimates between dual and single fuel benchmarks."

29 Utility Warehouse acquired the majority of its customers via a deal with a large supplier, offers energy services bundled with telecoms, and acquires new customers from 'partners' rather than by advertising. Cooperative Energy, with about $1 \%$ of the market, "is a considerably smaller supplier than First Utility and Ovo Energy with indirect costs on a per customer basis which were significantly higher than those of Ovo Energy and First Utility ... This suggests that it may not yet be operating at an efficient scale". (para 10.25)

30 "10.114 We note also that detriment calculated under the direct approach is similar to the net profits earned by the Six Large Energy Firms from their sales to domestic customers from 2012 to 2014, but significantly higher than our estimate of excess profits from domestic sales over this period. The implication is that there is a material degree of inefficiency in current prices (i.e., if prices were to decline to the competitive level, the Six Large Energy Firms would need to reduce their cost bases substantially in order to make profits in line with their cost of capital)." (p 629). 


\subsection{Did the CMA's benchmark comply with its Guidelines?}

Not surprisingly, the large suppliers challenged the CMA's assumptions, adjustments and calculations. The CMA briefy summarised these challenges and how it accepted or rebutted them. ${ }^{31}$ Unfortunately, because the CMA's precise calculations were either not set out or were redacted, they remain unknown and therefore not capable of properly informed appraisal and challenge. ${ }^{32}$ Oxera (2016), advising one of the large suppliers, argued that if the CMA had made what Oxera considered proper adjustments to the costs of the mid-tier suppliers, this could more than wipe out the alleged customer detriment. ${ }^{33}$

The focus here is on the underlying principle of the benchmark. CMA Guidelines explain that the market may be judged against a benchmark of a "well-functioning market", described as "one that displays the beneficial aspects of competition ... but not an idealized perfectly competitive market. The benchmark will generally be the market envisioned without the features [that give rise to the adverse effect on competition]". The Final Report cited this in the context of another adverse effect (absence of locational pricing for transmission losses, para $5.43 \mathrm{fn} 22 \mathrm{p} \mathrm{192),} \mathrm{but} \mathrm{made} \mathrm{no}$ conscious attempt to consider what the competitive retail market would have looked like without weak customer response and with customers engaging 'normally'. And the competitive conditions that the CMA specified were quite idealized.

"10.27 We have based our assessment on the principle that a competitive benchmark price in the domestic retail energy markets should fulfil the following criteria: $(a)$ it should be reflective of the prices charged to active/engaged customers; $(b)$ it should be reflective of the costs of an energy supplier which has reached an efficient scale (i.e. a large supplier) and which is in a steady state (i.e. the supplier that is neither growing nor shrinking rapidly); and (c) it should generate revenue that is consistent with a normal return (equivalent to an average EBIT margin of 1.25\%).” (p 605)

In consequence of this idealized benchmark, the adjustments that the CMA had to make to the actual costs of the comparator suppliers were very significant. The CMA ended up comparing actual prices of the six large suppliers with the CMA's guess at what just two of the much smaller mid-tier suppliers would charge if they were not exempt from costly environmental obligations and if they had reached an

\footnotetext{
${ }^{31}$ Final Report paras 10.67-10.80, pp 616-620. For a more extensive summary with references to suppliers' submissions, and minimal answers from the CMA, see Final Report Appendix 9.11 Annex B.

${ }^{32}$ The Final Report including appendices has over 10,000 redaction signs. During the investigation there was limited availability of confidential data, in a monitored data room, and even then not to suppliers but only to their authorized advisers.

${ }^{33}$ Oxera estimated that the correct detriment figure could be anywhere between $£ 0.7$ bn (half of the CMA's estimated $£ 1.4$ bn detriment) and minus $£ 0.7$ bn (implying that the large suppliers were actually more efficient than the entrants). The Final Report then made significant further adjustments after the data room closed, so that the final calculations could not be scrutinised by anyone and were not subject to consultation. These final adjustments were apparently not negligible: Oxera estimated that they were about $£ 1$ bn - in other words, of the same order of magnitude as the claimed detriment itself. But since the detail was redacted in the Final Report, literally no one other than the CMA panel knows or can know what the final calculations actually were. Friend (2016) expressed understandable concerns.
} 
efficient scale and if they were in a steady state and if they were not loss-making and if instead they were earning a normal return on capital.

As noted, the CMA acknowledged that its benchmark price was "a hypothetical construct", but how this hypothetical construct differed from "an idealized perfectly competitive market" was not explained. And if it was inappropriate for the CMA to use an idealized perfectly competitive market as a benchmark, why did not the same prohibition apply to the particular idealized hypothetical construct that the CMA did use? And how, finally, is the concept of "a competitive benchmark price" (singular) "in a steady state" to be reconciled with the insistence in the CMA Guidelines (para 10) that "competition is a process of rivalry", involving "cutting prices, increasing output, improving quality or variety", all of which imply differences between firms in efficiency, cost and price at any point in time, as well as differences and changes over time?

\subsection{Contrast with the CC's approach to calculating detriment}

The contrast noted above with the CC's investigation of the cement case stands out. Both investigations measured customer detriment as the difference between actual market price and a calculated competitive market price, multiplied by total demand. But whereas the $\mathrm{CC}$ defined the competitive market price as the unit cost of the least efficient plant required to meet capacity, the CMA defined the competitive price as the unit cost of the most efficient suppliers in the market. This must go a long way to explaining the differences in magnitude involved. The present subsection tries to assess the possible impact of this, and considers whether some intermediate position would have been more realistic.

The CMA did not include a diagram illustrating its approach, but a variant of the $\mathrm{CC}$ cement diagram can be constructed. This is not straightforward because of the extensive redactions in the Final Report. However, Table 2 shows some Ofgem data on market shares and supplier indirect costs for the periods used in the CMA

Table 2 Retail energy market data. Sources: Ofgem data portal and Segmental Accounts. Market share for 2012-2015(Q2) is shown at the mid-point, between Q3 and Q4 2013. The market shares shown are a rough average of the shares for electricity and gas

\begin{tabular}{|c|c|c|c|c|c|c|}
\hline \multirow[t]{2}{*}{ Supplier } & \multicolumn{2}{|l|}{ Market share } & \multicolumn{2}{|c|}{$\begin{array}{l}\text { Average annual indirect } \\
\text { cost per domestic } \\
\text { customer account (£) }\end{array}$} & \multicolumn{2}{|c|}{$\begin{array}{l}\text { Average domestic supply } \\
\text { profit margin (EBIT as \% } \\
\text { of revenue) }\end{array}$} \\
\hline & $\begin{array}{l}2012-2015 \\
(\mathrm{Q} 2)(\%)\end{array}$ & $\begin{array}{l}2015 \\
(\mathrm{Q} 2)(\%)\end{array}$ & $\begin{array}{l}2012-2015 \\
(\mathrm{Q} 2)\end{array}$ & 2015 & $\begin{array}{l}2012-2015 \\
(\mathrm{Q} 2)(\%)\end{array}$ & $2015(\%)$ \\
\hline SSE & 17 & 15 & 60 & 73 & 5.6 & 6.3 \\
\hline Entrants & 4 & 11 & 62.50 & 72.50 & & \\
\hline SP & 11 & 10 & 65 & 72 & 5.1 & 5.7 \\
\hline EON & 15 & 14 & 73 & 79 & 3.8 & 4.4 \\
\hline Centrica & 30 & 29 & 73 & 88 & 6.1 & 7.1 \\
\hline EDF & 11 & 11 & 89 & 88 & -1.8 & -0.7 \\
\hline RWE & 12 & 10 & 90 & 116 & 1.8 & -6.8 \\
\hline
\end{tabular}


calculations, viz. 2012-2015 (Q2), and 2015 alone. ${ }^{34}$ The average indirect costs of the six large suppliers ranged from $£ 60$ to $£ 90$ per customer account during the longer period, and from $£ 73$ to $£ 116$ in 2015 . Based on various CMA comments, the average new entrant unit cost per customer account is assumed to be mid-way between the two lowest cost large suppliers, although strictly speaking this is the assumed cost of the two most efficient of the new entrants. ${ }^{35}$

Figure 2 presents this data for the longer period 2012-2015(Q2) in a comparable format to the cement market in Fig. 1. It shows the new entrants (in aggregate) and the six large suppliers. The horizontal axis shows the average size of each supplier during this period, in terms of number of customer accounts and percentage of total $50 \mathrm{~m}$ customer accounts. ${ }^{36}$ The vertical axis shows the suppliers' average indirect cost per customer account.

During the period 2012-2015, the least efficient energy supplier was RWE with an average indirect cost of $£ 90$ per customer account. In contrast, the cost of the two most efficient new entrants is here assumed to have been about $£ 62.50$. The difference in the two bases of calculation amounts to $(£ 90-£ 62.50) \times 50 \mathrm{~m}$ customer accounts $=£ 1.375$ bn per year-in other words, about the same as the CMA's estimated average detriment of $£ 1.4$ bn.

The picture is similar for the single year 2015, where RWE's indirect cost was $£ 116$ compared to the entrants' assumed cost of $£ 72.50$. This implies a difference of $£ 2.175$ bn, which slightly exceeds the CMA's estimated detriment of $£ 2$ bn.

This is not to say that these indirect cost figures are the most appropriate basis for estimating competitive prices, or that the highest cost existing supplier would necessarily be the most appropriate basis for any calculation of detriment in the retail energy market. Rather, the point is that the choice of approach is evidently critical, and if the CMA had adopted the approach in CC Cement there would have been no detriment. This raises the question which, if either, of these particular approaches is appropriate.

\subsection{Which (if either) approach is more appropriate for the retail energy market?}

One argument might be as follows: The CC's approach was appropriate for the cement market because, in that sector, it is reasonable to assume that each cement

\footnotetext{
34 Note that these indirect costs do not include wholesale, network and other costs, so they do not constitute final retail prices to customers. They include operating costs such as sales and marketing, bad debt costs, costs to serve, IT, HR, finance, property, staffing and billing and metering costs (including smart meter costs). The figures do not include depreciation, tax or a return on capital.

35 The CMA indicated that its two chosen mid-tier suppliers were more efficient than the lower quartile of the six large suppliers but that at least one large supplier had lower indirect costs. (Para 10.98a) It also said that "Based on our analysis [of indirect cost ratios], Ovo Energy would be ranked joint first with SSE over the period under consideration, with Co-operative Energy ranking third, ahead of Centrica, E.ON, RWE and [^<]." (Appendix 9.11 para 27). The other two mid-tier suppliers were said to be higher cost. Little was (and is) known about the costs of the other smaller entrants. For simplicity, all entrants are shown in Fig. 2 at the same efficient cost.

$3620 \mathrm{~m}$ dual fuel customers take both gas and electricity from the same supplier, $3 \mathrm{~m}$ customers purchase gas and electricity from different suppliers and $5 \mathrm{~m}$ customers purchase electricity only.
} 


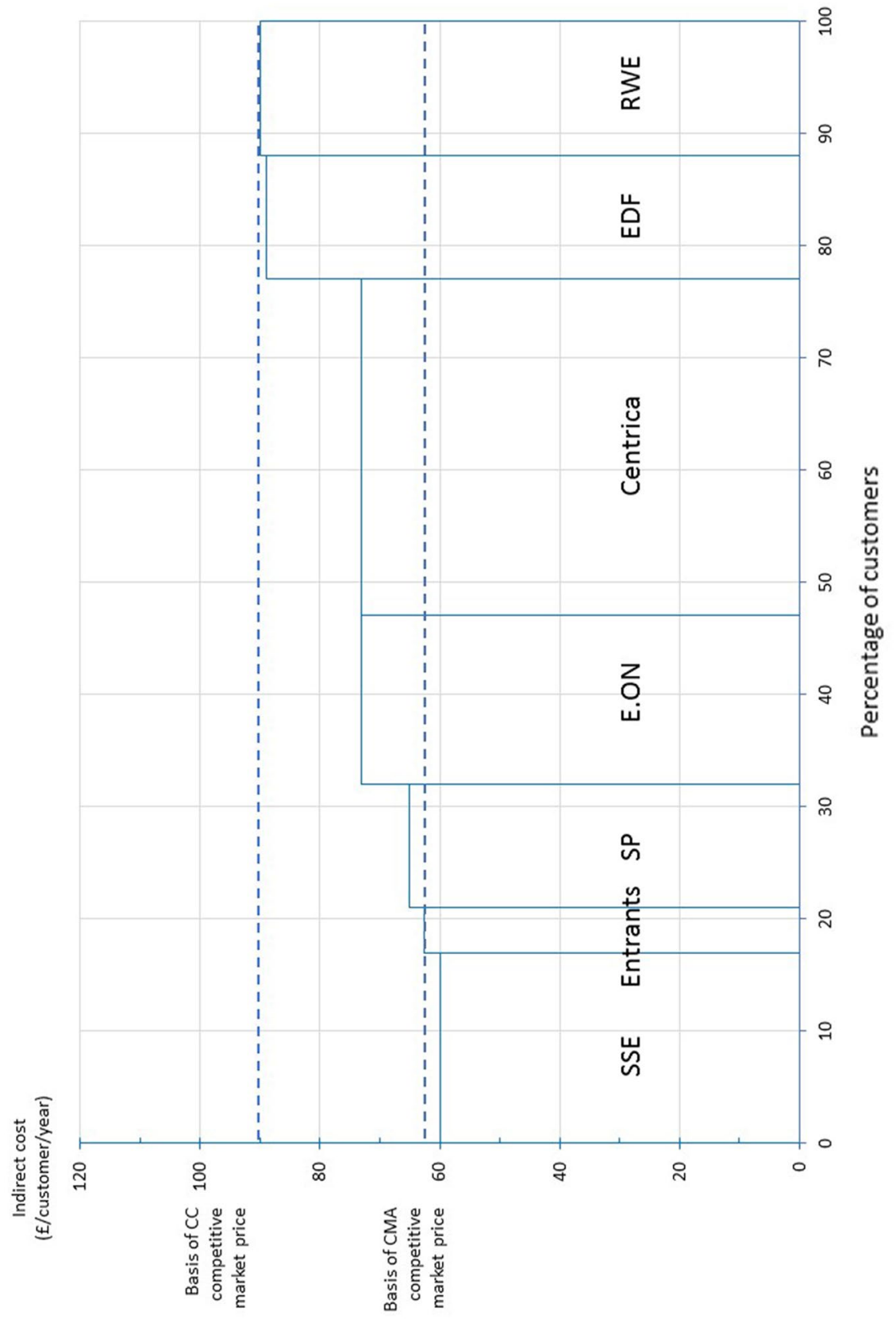

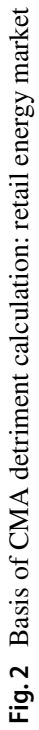


plant has a fixed production capacity and that new plants will have higher costs than existing plants because the most productive sources of raw materials will be accessed first. So competition will tend to drive prices towards the cost of the highest cost existing plant required to meet demand. In contrast, there is no obvious limit on the number of customers that can be served by any retail energy supplier, and new entrant suppliers seem to be lower cost than most existing ones. Hence competition will again drive prices towards the cost of a new entrant supplier, but in this case this is approximately the lowest cost supplier in the market. So the CMA's approach is more appropriate for the retail energy market.

As regards the first part of this argument, there was not in fact a fixed capacity of production at each cement plant. Rather, this was an assumption by the CC that "excludes large step changes in cost associated with increasing capacity or bringing mothballed capacity back on stream" (Cement Appendix 8.6 para 26(b)). Nor were new cement plants necessarily higher cost than existing ones. Indeed, "the CC's profitability analysis assumed that newer plants were more efficient" (Cement para 64) (although it was also implied that this was not the case for two particular older plants relative to a particular newer one).

This suggests that the $\mathrm{CC}$ was not led to its chosen approach in Cement by technology and relative costs over the long run. Rather, it took the (reasonable) view that a short-run perspective on a competitive price, taking as given existing costs and capacities, was more relevant and appropriate for judging the competitiveness of the market, and more consistent with the CC's Guidelines.

The second part of the argument involves empirical propositions about capacities and costs in the retail energy market that deserve exploration. If true, they suggest that the CC Cement approach is not appropriate. But this does not necessarily mean that the CMA Energy approach is best. Is the distance from a potential long run position the most appropriate basis for assessing the competitiveness of the market at a particular point in time? Did the CMA's benchmark in Energy reflect the levels of cost that might have been observed in a competitive retail energy market as it plausibly would have been in 2012-2015, in the hypothesised absence of weak customer response? Or was it a characterisation of an idealized, perfectly competitive equilibrium, assuming that all customers considered this to be a homogenous product, and that one or a few firms could have supplied the whole market at the assumed efficient cost?

Section 4 now explores in turn the concepts of weak customer response and product homogeneity, and the ability of firms to supply the market at efficient cost. It then looks at some calculations using arguably more realistic assumptions.

\section{Alternative models and calculations}

\subsection{Weak and normal customer response}

The CMA concluded that there was "weak customer response" because many customers had not switched to the smaller lower price suppliers, even though the CMA considered that energy was a homogeneous product and that the smaller suppliers 
gave at least as good customer service. This concept of weak customer response has been much debated, with a variety of complementary or competing explanations being proposed. ${ }^{37}$

The CMA's description of competition as a process of rivalry does not imply that customer reaction is immediate. Rather, since competition is a rivalrous discovery process over time it is to be expected that, at any point in time, some customers will not yet have discovered the better opportunities available. ${ }^{38}$ Kirzner $(1973 \mathrm{ch}$ 4, 1997ch V) has argued that it is not sufficient simply to produce a cheaper or better product and assume that customers will realise this: it is necessary not only to inform but also to convince customers that this is the case. ${ }^{39}$ This remains a challenge for many entrants, albeit one that they are tackling, as explained further below.

Whether it is appropriate to define a benchmark based on what a market would have been like if people were different is debateable. But if, for the sake of argument, one were to accept the CMA premise, that suppliers are able to price higher because customer response is weaker (or less informed) than it might be, this raises the question what would constitute "normal" or "reasonable" customer response? How to distinguish between a "genuine" preference for the existing supplier or aversion to another supplier, and an abnormally "weak" response to available market opportunities? And how much greater switching of supplier would have been normal? The CMA assumed, in effect, that the absence of weak customer response would be characterised by perfect knowledge and lack of preference for, or loyalty to, particular suppliers. This is implausible. But what might the CMA more reasonably have assumed?

The compromise suggestion here is to consider as a possible benchmark the information that became available (ex post) as a result of the CMA's recommendation that Ofgem should experiment with different ways of promoting greater customer engagement and switching. In a series of customer engagement trials known as collective switch (Ofgem 2019), Ofgem required a number of large suppliers to offer to a sample of their long-standing (assumed disengaged) customers a

\footnotetext{
37 Ofgem and the CMA have been much influenced by behavioural economics (Ofgem 2011; Littlechild 2016; Chisholm 2016; Walker 2017). Economists had previously explored this perspective (Ek and Söderholm 2008; Defeuilley 2009; Wilson and Waddams Price 2010; later Flores and Waddams Price 2018; He and Reiner 2017). Brennan (2007) and Yarrow (2015) suggested that some customers may have a preference not to choose. Littlechild (2018b) argued that the realistic opportunities for saving money by switching supplier were lower than the CMA suggested, that engagement was not less than for other products, and that the costs and risks of engagement or of other products were higher than appeared. Hortaçsu et al. (2017) find inertia greater for lower income neighbourhoods, though the difference declines over time. Mountain and Burns (2020) find that switchers save money compared to remainers, but the difference in bills is small compared to the savings available, and moreover this differs by size of retailer. Deller et al. (2017) and Ros (2020) find that the evidence is consistent with customers making rational economic decisions.

38 Thus, "when the variety of near-substitutes is great and rapidly changing, where it takes a long time to find out about the relative merits of the available alternatives, ... the adjustment must be slow even if competition is strong and active". (Hayek 1946, p 103).

39 Similarly, in marketing, the "better mousetrap fallacy" is the mistaken belief that a superior product will automatically generate customers, which would remove the need for building that "path to your door" through a strong marketing plan.
} 
collectively-negotiated "exclusive deal", and gave considerable support to those customers that expressed interest in switching either to the proposed new supplier or to any other. Some $25 \%$ of these customers then switched supplier. By implication, the remaining $75 \%$ of customers preferred their own supplier, or at least preferred not to switch, even though they now knew there was a lower priced offer available.

So, for the present exercise, assume that with "normal" or "reasonable" as opposed to "weak" customer response, $25 \%$ of the customers of the higher cost suppliers would have switched to lower cost suppliers. (This is not claimed to be an "ideal" or politically acceptable switching rate, simply one that, with the benefit of hindsight, might be argued to be more realistic than a $100 \%$ rate.) The remaining $75 \%$ of customers are assumed to prefer their present supplier, so the higher prices they pay are not to be taken as an indication of customer detriment due to weak customer response. The detriment applies only to those $25 \%$ of customers that would have switched had their response not been "weak". This immediately cuts the potential magnitude of the customer detriment by $75 \%$ : from $£ 1.4$ bn to $£ 350 \mathrm{~m}$ for the 2012-2015 period as a whole, and from $£ 2$ bn to $£ 500 \mathrm{~m}$ for 2015 .

\subsection{Efficiency and potential output of the industry participants}

The next stage is to consider whether suppliers could have accommodated their initial customers plus these additional ones at the postulated "efficient cost", or whether some other level of cost would be more plausible. The CMA Energy benchmark was an efficient cost that was apparently achieved only by two mid-tier suppliers, accounting together for under $4 \%$ of the total market (over that period), and also by one large supplier (SSE) with $17 \%$ of the market, hence a total of under $21 \%$ of customers. The costs of other large suppliers and two other mid-tier suppliers were higher, and the costs of smaller new entrants were generally unknown (though in one case higher). Consider in turn the candidates for such expanded output at "efficient cost".

The six large suppliers had previously been able to supply, in aggregate, the $11 \%$ of the market that the entrants had taken from them by 2015, so could presumably have accommodated at least that many more customers now, albeit perhaps with some extra expenditure. But would they have been as efficient as the two mid-tier suppliers entrants were claimed to be?

This seems unlikely. EDF, $84 \%$ owned by the French Government, and focused on getting support for building a new UK nuclear reactor, seemed impervious to its high retail costs and associated financial losses. The other large suppliers were privately owned companies subject to stock market pressures. Why would they have chosen to exercise market power in the form of inefficient costs and sometimes losses or borderline coverage of their cost of capital, if there was a straightforward way to reduce those costs?

In fact, the large suppliers had already been actively seeking greater efficiency in order to compete effectively. In the early 2010 s their priority was to unify and modernise their paper-based legacy IT and billing systems. Four of the large suppliers (and to a lesser extent a fifth) invested heavily in adopting the system then 
considered to be the best available, namely the SAP system. ${ }^{40}$ In the event, the customisation and integration of these systems proved significantly more problematic, time-consuming and expensive than expected (especially for Centrica and RWE). In some cases it led to temporary failures in customer service and increases in customer complaints. In retrospect, it might be argued that these suppliers should have acted differently, but there was no obviously better system available at the time, and they learned only from experience about the problems and costs involved. Also, since it was precisely the threat of losing customers and the aim to gain new onesthat is, the strength of customer response not the weakness of it-that caused these suppliers to act as they did, it seems implausible that stronger customer response would have led or enabled these large suppliers to operate at the CMA's assumed efficient costs.

One large supplier (SSE) did not adopt the SAP system, thereby avoiding the significant cost and disruption of doing so. Table 2 suggests that, as of 2012-2015, it had the lowest average indirect cost per customer. But this did not mean it was more efficient: as SSE explained to the CMA, its costs were unrepresentative because it had not yet invested in a new system. ${ }^{41}$ In consequence, it did not have an adequate IT and billing platform going forward. This limited its effectiveness (and was later cited by commentators as a reason why it needed to merge with another supplier that did have such a platform). So it is unlikely that SSE could have expanded its own customer numbers significantly, or even maintained its low cost with adequate customer service, had there been stronger customer response.

What about the medium or mid-tier suppliers? The apparently most successful and efficient medium supplier, hailed by the CMA, was Ovo. It reported 171,000 customers in March 2014, which more than doubled to 408,000 customers by December 2014. It was acclaimed as "the tenth fastest-growing private company in the UK", so this growth was evidently exceptional. Its target was $1 \mathrm{~m}$ customers by end 2017, which it achieved. To do so, it invested heavily in IT and new technology. The picture is not entirely rosy, however. Ovo recently admitted systems and compliance failings going back to 2015 , leading Ofgem to accept an $£ 8.9 \mathrm{~m}$ compliance payment, observing that "Ovo expanded rapidly, but did not adequately prepare for the demands of such an expansion." The criticism was severe, suggesting that Ovo's apparent low cost was at the expense of effiency, investment and regulatory compliance. $^{42}$

\footnotetext{
40 Systems Applications and Products, the name of the software as well as the German company that developed it. There is some discussion of investment in billing systems and software in Final Report Appendix 9.10 paras 49-57, albeit without the detail noted here.

41 SSE told the CMA "that its indirect costs were materially reducing the ... cost benchmarks used by the CMA [... because] it would expect to have lower indirect costs than other firms, since it was at a different point in its investment cycle for domestic customers." (Appendix 9.11 para 12).

42 "Ovo chose an IT system that did not contain functionality to produce documents that were mandatory and deferred the costs of full regulatory compliance." (para 2.13) "Ovo admitted it was unable to produce final bills for its prepayment meter customers and that this functionality did not exist within its billing system." (para 2.40) "Ovo could have invested more in policies, procedures and processes in respect of billing, annual statements and statements of account. The Authority found that Ovo lacked in
} 
The Final Report noted three other mid-tier suppliers (apart from Utilita that specialised in prepayment meter customers), namely First Utility (now Shell Energy), Utility Warehouse and Co-op Energy. The last was smaller than Ovo, and had significantly higher indirect costs, which the CMA attributed to not yet operating at an efficient scale. (para 10.25) It subsequently incurred financial losses and sold its customers to another supplier. What is remarkable about these three companies is that, on the one hand, they grew remarkably rapidly over the previous few years, then subsequently recorded no increase at all in market shares after 2014 (having, respectively, $3 \%, 2 \%$ and $1 \%$ of the total market according to Ofgem's data portal). So is there reason to expect that they would have had, or could have coped with, significantly higher market shares had more customers been more engaged in the market?

What about smaller (at the time) new entrants? During the early 2010s, improved and lower cost IT and billing and collection systems were being developed, geared to quick and small scale entry. ${ }^{43}$ These systems were popular and enabled a flurry of new entrants (83 from 2013 to 2019). However, the plausible extent of such growth was not obvious at the time of the CMA investigation. It is not clear that the entry or growth of these suppliers were hindered by weak customer response, or would or could have been significantly faster with more engaged customers, or that their systems could have coped with millions rather than thousands of customers.

Moreover, the overall costs and efficiency of these smaller suppliers were and are unclear. The precise costs of many entrants are largely unknown, certainly in the detail that the large suppliers are obliged to provide. To various degrees they were exempt from various social, environmental and other regulatory obligations (including smart metering installation) that applied to large and medium suppliers, so were in effect cross-subsidised by the larger suppliers and their customers. Many small suppliers underestimated the costs and risks involved in the supply business. Almost all new suppliers have made financial losses over many years, and most are still doing so. ${ }^{4}$

Some newer entrants have grown remarkably since the CMA investigation, notably Bulb and Octopus which have each taken about $5 \%$ of the market in 5 years and offer either a single variable tariff (Bulb) or a closely clustered range of tariffs (Octopus). Octopus has developed Kraken, a new cloud-based IT platform for interacting

\section{Footnote 42 (continued)}

these areas." (para 2.74) "A recurring theme in this investigation was Ovo's lack of effective regulatory compliance mechanisms and generally poor attitude to compliance. Regulatory compliance was often disregarded or deprioritised in favour of other business activities. It was also not adequately factored into Ovo's growth plans." (para 3.11) "It should also have been apparent that the continued deprioritising of issue rectification would ultimately result in breaches of licence conditions. We regard this behaviour as reckless." Ofgem Penalty Notice 29 January 2020, para 4.18, preceding quote para 3.12.

43 E.g. off-the-shelf or "supplier in a box" models that had been taken through Ofgem and other entry processes, that could be rented rather than purchased outright, and that increasingly also offered outsourced customer management services and related support infrastructure.

44 The latest accounts for 33 small and medium suppliers collected at https://mikewhiskeytango.com/ profit/ show that 5 made an operating profit and 24 made an operating loss. The remaining 4 are failed businesses whose customers were rescued under the Supplier Of Last Resort (SOLR) arrangement. 
with customers and the industry, and has taken over nine smaller suppliers. Bulb and Octopus are each aiming at $100 \mathrm{~m}$ customers internationally within the decade. To date, however, they have both run at significant financial deficits in order to grow. ${ }^{45}$

At the same time, some established international energy companies (Engie and Vattenfall) have sold out of the market because of the strength of competition, and some 20 other small (and some medium) suppliers have gone bust, unable to sustain a profitable business in the face of lack of scale economies (and often inadequate business experience), fluctuating wholesale costs (which they had not adequately hedged) and fierce competition. Often, these exiting suppliers imposed costs on other larger suppliers (and their customers) as Ofgem put in place measures to protect the customers of failing businesses.

Other events since the CMA investigation reveal how dramatically the competitive market discovery process is working. While three of the six large suppliers (Centrica, EDF and SP) seem to have focused on operating cost reductions, a fourth (SSE) has just been taken over by one of the CMA-identified efficient mid-tier suppliers (Ovo), which has also taken over another eight small suppliers. The fifth large supplier (E.ON) took over the sixth (RWE) and subsequently contracted to adopt Octopus's Kraken platform, since when Octopus has entered an agreement to provide Kraken to Origin Energy in Australia.

All this suggests that, even if the larger suppliers in 2016 were inefficient relative to the technology available 4 years later, the market was nonetheless extremely competitive, and is evolving in ways that could not have been forecast in any detail. But it does not suggest that the market was inefficient relative to the technology available at the time of the Final Report, nor that costs of then-existing companies would have been significantly lower if customers had been more engaged than they actually were.

\subsection{An alternative benchmark and calculation}

If the CMA's cost benchmark was not plausible, what would a more appropriate benchmark have been, assuming (a) that customers had exhibited a "normal" rather than "weak" response, and (b) that the relevant technologies and costs were those obtaining before and during the period 2012-2015 rather than later, but also (c) that there would have been some capability to increase the number of customers with the lower cost suppliers.

All these are necessarily a matter of conjecture, but to give some indication of possible magnitude, suppose (a) as suggested above, that "normal" customer response would have meant that $25 \%$ of the customers of the higher cost suppliers would have switched to lower cost existing suppliers, and (b) that each lower cost supplier could and would have supplied up to $25 \%$ more customers in the relevant period, at its existing indirect cost per customer.

The available data do not allow a calculation of what price would have established itself in a benchmark competitive market so defined. However, it is possible

\footnotetext{
45 For the financial year ending March/April 2019, operating loss was $£ 34 \mathrm{~m}$ for Octopus, $£ 128 \mathrm{~m}$ for Bulb.
} 
to estimate by how much the benchmark competitive cost would have been different from that assumed by the CMA, assuming it was set at the margin (as per the Cement case) for those customers that were mobile as between suppliers, rather than at a level equal to that of the two most efficient new entrants.

Take first the period 2012-2015 as a whole, as summarised in the previous Table 2 and Fig. 2. The above assumptions imply that a quarter of their customers would have left highest cost suppliers RWE and EDF, amounting to $6 \%$ of all customers in the market $(=25 \% \times(12+11) \%)$. Of these, $5 \%$ would have gone to SSE and new entrants (reaching the limit of their assumed capacity), the other $1 \%$ to SP. It is assumed that SP could continue to take customers from E.ON and Centrica, but would not be able to take all those that would be willing to leave. So at the margin, the average annual indirect cost per customer would be that of E.ON and Centrica, jointly equal to $£ 73$. This compares with the CMA's benchmark of the new entrant indirect cost per customer, assumed here to be $£ 62.50$. If what is argued here to be the more realistic benchmark cost had been chosen, the reduction in customer detriment from the CMA's calculation, for the $25 \%$ of customers assumed to be responsive, would have been $£(73-62.50) \times 50 \mathrm{~m} \times 0.25=£ 131.25 \mathrm{~m}$. So the net customer detriment would be $£(1.4 \mathrm{bn} \times 25 \%)-£ 131.25 \mathrm{~m}=£ 218.75 \mathrm{~m}$.

Applying the same calculation to the final year 2015, RWE, EDF and Centrica which had $50 \%$ of all customers in the market would have lost a quarter of these $(12.5 \%)$ to the other four suppliers. At the margin, the average annual indirect cost was between EON at $£ 79$ and Centrica/EDF at $£ 88$, say midpoint $£ 83.50$. So the reduction in customer detriment compared to the CMA assumption is about $£(83.50$ $-72.50) \times 50 \mathrm{~m} \times 0.25=£ 137.50 \mathrm{~m}$, and the net customer detriment for this $25 \%$ of customers in 2015 would be $£(2 \mathrm{bn} \times 25 \%)-£ 137.50 \mathrm{~m}=£ 362.50 \mathrm{~m}$.

These are very rough and illustrative calculations, and alternative assumptions would yield different answers. ${ }^{46}$ The main point remains, however. With more realistic assumptions about what a 'well-functioning retail energy market' might have looked like, the customer detriment according to the CMA's direct approach would have been significantly lower, of the order of $£ 200 \mathrm{~m}$ rather than $£ 1.4$ bn for the period as a whole, and around $£ 360 \mathrm{~m}$ rather than $£ 2$ bn for 2015 .

\section{The CMA's indirect approach}

The preceding discussion has focused on the CMA's 'direct approach'. This section briefly examines the CMA's 'indirect approach', which "involves assessing both: (i) the Six Large Energy Firms' levels of profitability (and in particular whether the return on capital employed by such suppliers exceeds their cost of capital); and (ii) the extent to which the Six Large Energy Firms have incurred

\footnotetext{
46 It might also be argued that, with more customers, the lower cost firms would be able to spread their overheads to secure lower average costs. But by the same token the higher cost firms would have fewer customers and higher average costs.
} 
overhead costs inefficiently (i.e. whether costs are higher than we estimate an efficient supplier would incur)". (para 2.164)

As regards (i), the CMA estimated that excess profit averaged $£ 303$ m per year over the relatively long period 2007-2014 and £650 m per year over the shorter more recent period 2012-2014.

As regards (ii), it estimated an average inefficiency cost of either $£ 420 \mathrm{~m}$ or $£ 850 \mathrm{~m}$ per year over 2007-2014, depending on whether the six large suppliers were benchmarked against their own lowest cost supplier or another (mid-tier) supplier.

To estimate the price detriment to customers, the CMA simply added these two calculations together. Over the longer period 2007-2014 this led to an average annual customer detriment of $£ 723 \mathrm{~m}(=£ 303 \mathrm{~m}+£ 420 \mathrm{~m})$ or $£ 1.153 \mathrm{bn}$ $(=£ 303 \mathrm{~m}+£ 850 \mathrm{~m})$, depending on which efficiency benchmark was used. Over the shorter and later period 2012-2014 the average detriment was $£ 1.070$ bn $(=£ 650 \mathrm{~m}+£ 420 \mathrm{~m})$ or $£ 1.5 \mathrm{bn}(=£ 650 \mathrm{~m}+£ 850 \mathrm{~m})$, again depending on the efficiency benchmark.

The CMA concluded that "The fact that these two approaches, which are based on different data sets and methodologies, provide similar estimates, gives us confidence that our overall conclusions on the level of detriment are robust" (para 10.112). The CMA placed "greater weight on the results produced using the direct method."

The addition of inefficient costs to excess profit is basically a continuation and implication of the CMA's assumption that the benchmark 'well-functioning market' should be characterised by all suppliers operating at or near efficient cost. The CMA itself noted that this made a significant difference to the overall calculation of detriment. For the longer period 2007-2014, and using the more aggressive efficiency benchmark, inefficiency is nearly three times the size of excess profit (850/303) and hence accounts for three quarters of the detriment.

However, this was a departure from standard practice. UK competition authorities have not routinely attempted to quantify the extent of inefficiency and its impact on market price, and then add such an adjustment to their estimate of excess profits (Littlechild 2020b, Appendix 2). Only two previous reports by the $\mathrm{CC}$ that predated market investigations did consider making such an adjustment, and both decided not to do so. The CC's 2003 Guidelines briefly mentioned the possibility of comparing actual costs with efficient costs but the CC market investigations listed in Table 1 did not do so. The 2013 Guidelines note that low profitability may be concealing ineffective competition and that firms with low profits might be inefficient with higher costs. "In some cases, the CC may be able to compare actual costs with efficient costs when looking at the level of profitability achieved by firms but this may not always be practical." (para 125) However, the centrality of a calculation of inefficient costs, and the addition of this to the calculated excess profit, is nowhere in the Guidelines. It seems unique to CMA Energy and its origins at Ofgem in 2008 (Littlechild 2016).

Thus, on the conventional CC aproach to calculating detriment, via excess profit without excess cost, as noted this averaged $£ 303 \mathrm{~m}$ per year over the longer period 2007-2014, and $£ 650$ m over 2012-2014. Even these are arguably an overestimate. 
Littlechild (2020b, Appendix 2) explains that the CMA assumed that a normal profit of $10 \%$ return on capital would imply an EBIT (Earnings Before Interest and Tax) margin of just over $1.9 \%$. But the achieved return in the Industrial and Commercial market (regarded as very competitive) would imply an EBIT margin of $2.4 \%$ (after adjusting for the difference in risk). Against that latter more practical benchmark, the excess profit would reduce by nearly a half, from $£ 303 \mathrm{~m}$ to about $£ 170 \mathrm{~m}$, over 2007-2014, and by a fifth, from $£ 650 \mathrm{~m}$ to $£ 517.5 \mathrm{~m}$, over $2012-2014$.

\section{Conclusions}

The exceptionally high detriments ( $£ 1.4$ bn or $£ 2$ bn) that the CMA identified in the retail energy sector do not indicate an exceptional lack of competition. Rather, they reflect a significantly different approach compared to previous UK competition authority investigations, in three main respects: first, the weight placed on "weak customer response" and the assumption that energy customers could and should have acted differently; second, the comparison against a hypothetical benchmark that effectively but implausibly assumes that, if only customers had been more engaged, all suppliers would have been as efficient as the most efficient suppliers then in the market; and third the augmentation of the conventional excess profit calculation by adding an element for inefficiency that, in one calculation, amounted to nearly three times the excess profit. More realistic (but still debateable) assumptions would have reduced the calculated detriments to fractions of the CMA's estimated levels.

The CMA's remedies did not seem to match its finding of large customer detriment. The CMA had been warned about the implausibility of its stance but did not modify its position. ${ }^{47}$ Its calculation fuelled a media demand for introducing widespread price controls, either absolute or relative, even though the CMA had explicitly advised against such controls. Not surprisingly, politicians responded. Unless the price cap is regarded as having other uses (e.g. to enable otherwise illegal coordination of "fair" prices to higher-cost vulnerable customers), a significant challenge now is how to remove it.

The CMA Energy approach thus seems inappropriate for future policy because it misrepresents the nature of competition (and of price differentials), and overstates the reasonable extent of market power and customer detriment. It thereby invites inappropriate and counter-productive government and regulatory intervention, some of which is already under consideration beyond the energy market.

What other lessons might be learned? "Weak customer response" was surely the Achilles heel of this investigation. The investigation was launched at a time when

\footnotetext{
47 "Overall we find it surprising that the majority of the CMA panel does not feel that stronger interventions are justified if they believe their detriment estimates are robust. Either the CMA has substantially overestimated the detriment of non-engagement or the majority of the panel are being extremely optimistic about their ability to raise consumer engagement." (Deller et al. 2016, p 5)
} 
the Government's official Steer said that the CMA should focus on this concept. ${ }^{48}$ The revision to the CC/CMA Guidelines had majored on this (Littlechild 2016). Fortunately, the next Steer from the next Government removed this guidance. The CMA could usefully consider further its own stance. ${ }^{49}$

As regards the estimate of customer detriment, surely a CMA market investigation should not assume that in a 'well functioning market' all competitors would be as efficient as the most efficient competitor at the time of the market investigation. How is this different from the "idealized perfectly competitive market" that the Guidelines explicitly and rightly reject? What then becomes of the CMA's stated belief in competition as a process taking place over time, which presumably means that some suppliers can be more efficient than others at any point in time, and that consumers are likely to face a range of prices? (And if a well-functioning competitive market is represented, not by the intersection of the market supply and demand curves, but by a price equal to, or near to, where the supply curve starts on the vertical axis, should the CMA start to rewrite the economics textbooks?)

This investigation has highlighted the difficulties in estimating customer detriment by reference to an efficient cost benchmark. Assumptions can be made [e.g. that existing companies cannot expand capacity (as in Cement) or that they can serve the whole of the market at present average cost (as in Energy)], which may have varying degrees of plausibility in different cases. But even in competitive markets, firms will have different costs for many different reasons (e.g. because they have different products or customers with different costs to serve, or they may provide different levels of customer service, or investments are made at different times with different technologies available, etc.). This suggests that previous competition authority investigations were right to be cautious about putting weight on such hypothetical "what-if" calculations of detriment rather than on more conventional calculations of excess profit (which, admittedly, have their limitations too). Moreover, previous investigations were right not to compromise their excess profit calculations by introducing conjectured excess costs.

If, as the CMA professess, "competition is a process of rivalry" then an investigation needs to compare processes rather than equilibrium states. It needs to look at possible limitations on the competitive process. This suggests putting less weight on calculations of customer detriment at a moment in time. And more weight on conventional competition criteria such as barriers to entry or expansion or to customer switching, none of which seem to have been problematic in the Energy market.

There are also wider institutional questions. For example, is it appropriate to steer the CMA towards a "strong dialogue with sectoral regulators ... to ensure that the overall competition regime is coordinated"-which in this case seems to have

\footnotetext{
48 "Markets sometimes fail to work effectively not because of lack of competition but because consumers struggle to compare products or face costs of switching. The Government considers that these consumer behavioural issues should be central to the CMA's analysis of whether markets are working well..." BIS, Competition Regime, Response to Consultation on Statement of Strategic Priorities for the CMA, 1 October 2013 .

49 Should the CMA be so ready to accept the concept of weak customer response? Should it give it such prominence in its Guidelines? If a CMA investigation does claim weak customer response, would it be salutary to require it to spell out more explicitly what would constitute a 'normal' customer response rather than implicitly assume some sort of economically optimal behavior?
} 
confirmed a mutual admiration for the concepts of weak customer response and "loyalty penalties", and a focus on cost inefficiencies? Or would it be better instead to maintain and affirm the importance of an independently minded competition authority as a check on the enthusiasms of the sector regulators-and conversely? There are also, perhaps, questions about the creation, direction and politicisation of the CMA. But these lie beyond the scope of this paper.

Open Access This article is licensed under a Creative Commons Attribution 4.0 International License, which permits use, sharing, adaptation, distribution and reproduction in any medium or format, as long as you give appropriate credit to the original author(s) and the source, provide a link to the Creative Commons licence, and indicate if changes were made. The images or other third party material in this article are included in the article's Creative Commons licence, unless indicated otherwise in a credit line to the material. If material is not included in the article's Creative Commons licence and your intended use is not permitted by statutory regulation or exceeds the permitted use, you will need to obtain permission directly from the copyright holder. To view a copy of this licence, visit http://creativecommons.org/licen ses/by/4.0/.

\section{References}

Brennan, T. (2007). Consumer preference not to choose: Methodological and policy implications. Energy Policy, 35(3), 1616-1627.

Chisholm, A. (2016). "Why 'sleepers' can't always be left to 'sleep"”, speech at conference on competition implications and social obligations in a digital world, CCRP 2016 Competition Policy Roundtable, London, 21 January, at https://www.gov.uk/government/speeches/alex-chisholm-on-consumer-engag ement-in-a-digital-world.

Competition and Markets Authority (CMA). (2016). Energy market investigation, final report, 24 June at https://www.gov.uk/cma-cases/energy-market-investigation.

Defeuilley, C. (2009). Retail competition in electricity markets. Energy Policy, 37(2), 377-386.

Deller, D., Giulietti, M., Loomes, G., Waddams Price, C., Moniche Bermejo, A., \& Jeon, J. Y. (2017). Switching energy suppliers: It's not all about the money. Working Paper 17-5, University of East Anglia, Competition Policy Centre, 21 August at: http://competitionpolicy.ac.uk/publications/workingpapers.

Deller, D., Hviid, M., Waddams, C. (2016). Competition and markets authority: Energy market investigation-Provisional decision on remedies. Consultation response from the Centre for Competition Policy, 8 April (posted 21 April) at https://www.gov.uk/cma-cases/energy-market-investigation.

Ek, K., \& Söderholm, P. (2008). Households' switching behavior between electricity suppliers in Sweden. Utilities Policy, 16(4), 254-261.

Fisher, F. M. (2002). Accounting profitability and monopoly rents, The case of small and medium sized banking enterprises in the UK, reprinted as Appendix 13.1 in CC (2002).

Fisher, F. M., \& McGowan, J. J. (1983). On the misuse of accounting rates of return to infer monopoly profits. American Economic Review, 73, 82-97.

Flores, M., \& Waddams Price, C. (2018). The role of attitudes and marketing in consumer behaviours in the British retail electricity market. The Energy Journal, 39(4), 153-179.

Friend, M. (2016). Unexplained mysteries of the energy market investigation. Competition Policy International, December.

Harris, C. (2015). Peak load and capacity pricing, theory and practice in electricity. New York, Basingstoke: Palgrave Macmillan.

Harris, C. (2019). Concluding the 40-year utilities experiment-death spiral or rebirth? Beesley Lecture, London, 23 October, available from drcpharris@gmail.com.

Hayek, F. A. (1946). "The meaning of competition", Stafford Little lecture, 20 May, reprinted as Chapter V in Hayek, Individualism and economic order. Chicago: Henry Regnery Company, 1948.

He, X., \& Reiner, D. (2017). Consumer engagement in energy markets: The role of information and knowledge. EPRG Working Paper 1835, Cambridge Working Paper in Economics 1867.

Hortaçsu, A., Madanizadeh, S., \& Puller, S. (2017). Power to choose? An analysis of consumer inertia in the residential electricity market. American Economic Review, 9(4), 192-226. 
Kirzner, I. M. (1973). Competition and entrepreneurship. Chicago, London: University of Chicago Press.

Kirzner, I. M. (1997). How markets work: Disequilibrium, entrepreneurship and discovery. IEA Hobart Paper No 133, London: Institute of Economic Affairs.

Littlechild, S. C. (2014). The competition assessment framework for the retail energy sector: Some concerns about the proposed interpretation. European Competition Journal, 10(1), 181-202.

Littlechild, S. C. (2016a). The CMA energy market investigation, the well-functioning market, Ofgem, government and behavioural economics. European Competition Journal, 11(2-3), 574-636.

Littlechild, S., et al. (2016b). Supplementary submission by former energy regulators on provisional decision on remedies, 20 April (posted 21 April) at https://www.gov.uk/cma-cases/energy-market-investigation.

Littlechild, S., et al. (2017). Submission to the house of lords economic affairs committee, investigation into the economics of UK energy policy, 20 January.

Littlechild, S. C. (2017a). "The CMA's analysis of the retail energy market: An examination using textbook economics", EPRG Working Paper series, University of Cambridge, 5 March.

Littlechild, S. C. (2017b). Competition and price controls in the UK retail energy market. ACCC Network, June: $1-10$.

Littlechild, S. C. (2018a). "The CMA's assessment of customer detriment in the GB retail energy market", 8 April 2018 (revised version of Littlechild 2017a).

Littlechild, S. C. (2018b). Competition, regulation and price controls in the GB retail energy market. Utilities Policy, 52(June), 59-69.

Littlechild, S. C. (2019). Promoting competition and protecting customers? Regulation of the GB retail energy market 2008-2016. Journal of Regulatory Economics, 55, 107-139.

Littlechild, S. C. (2020a). The evolution of competitive retail electricity markets, 5 April, chapter 4. In J.-M. Glachant, P. L. Joskow, \& M. Pollitt (Eds.), Handbook on the economics of electricity markets (forthcoming).

Littlechild, S. C. (2020b). The CMA's assessment of customer detriment in the UK retail energy market (May 28, 2020). Available at SSRN: https://ssrn.com/abstract=3612737.

Littlechild, S., McCarthy, S. C., Marshall, M., Smith, S., \& Spottiswoode, C. (2016a). Response by former $G B$ energy regulators to CMA provisional decision on remedies, 11 April (posted 21 April) at https:// www.gov.uk/cma-cases/energy-market-investigation.

Long, W. F., \& Ravenscraft, D. J. (1984). The misuse of accounting rates of return: Comment. American Economic Review, 74(2), 494-500.

Mountain, B., \& Burns, K. (2020). "Loyalty taxes in retail electricity markets: Not as they seem?" Victoria Energy Policy Centre, VEPC working paper 2005, Victoria Energy Policy Centre May at https://www. vepc.org.au/.

Ofgem. (2011). What can behavioural economics say about GB energy consumers? 21 March.

Ofgem. (2019). Insights from Ofgem's consumer engagement trials: What works in increasing engagement in energy tariff choices? 27 September.

Oxera. (2016). Critique of CMA direct benchmarking analysis, A note for Scottish Power based on a nonconfidential submission to the CMA, 12 April, attached to Scottish Power response to CMA provisional decision on remedies, 22 April at https://www.gov.uk/cma-cases/energy-market-investigation.

Ros, A. (2020). "Does electricity competition work for residential consumers? Evidence from demand models for default service and competitive residential electricity services" presented at the $38^{\text {th }}$ Annual Rutgers Center for Research in Regulated Industries (CRRI) Eastern Conference, May 29-31, Shawnee on Delaware, Pennsylvania. https://www.researchgate.net/publication/339912029_Does_Electricity_ Competition_Work_for_Residential_Consumers_Evidence_from_Demand_Models_for_Default_Servi ce_and_Competitive_Residential_Electricity_Services.

Walker, M. (2017). Behavioural economics: The lessons for regulators. European Competition Journal, $13(1), 1-27$

Wilson, C., \& Waddams Price, C. (2010). Do consumers choose the best suppliers? Oxford Economic Papers, 62, 647-668.

Yarrow, G. (2015). Submission on the CMA's summary of provisional findings report and notice of possible remedies, posted 2 September at https://www.gov.uk/cma-cases/energy-market-investigation.

Publisher's Note Springer Nature remains neutral with regard to jurisdictional claims in published maps and institutional affiliations. 